\title{
A FUNÇÃO APAZIGUADORA DOS RITUAIS NAS ORGANIZAÇÕES
}

\author{
Luiz Carlos A. Iasbeck Doutor em Comunicação e Semiótica pela PUC de São \\ Paulo. Pesquisador Associado no Programa de Mestrado \\ da Faculdade de Comunicação da Universidade de \\ Brasília, Professor da Universidade Católica de Brasília \\ e na UPIS-DF. Vice Presidente da Associação Brasileira \\ de Semiótica é o atual Representante da FELS para o \\ Brasil.
}

\begin{abstract}
Resumo
Passamos grande parte de nossas vidas envolvidos em Organizações, grupos sociais e profissionais nos quais os inevitáveis conflitos de interesses são amenizados por práticas rituais. Os ritos atualizam mitos, reforçando, assim, os fundamentos e as forças aglutinadoras que justificam a existência das organizações. $\mathrm{Na}$ base dessas práticas encontramos uma tendência unificadora do mundo, herdada da mitologia clássica, que está na origem da necessidade de comunicar.
\end{abstract}

Palavras-chave: Semiótica; Organizações; Mitologia.

\section{THE SOFTER FUNCTION OF THE RITUAL ACTS IN THE ORGANIZATIONS}

\begin{abstract}
We spend a large part of our lives dealing with organizations, social and professional groups at which the conflicts of interests are softened by ritual practices. The rites update the myths, reinforcing, in this way, the principles that justify the existence of the Organizations. In the core of these practices, we find an unifying trend of the world, that is a heritage of the classical mythology. This trend is also in the origin of human communication.
\end{abstract}

Keywords: Semiotics; Organizations; Mythology.

Uma das práticas mais comuns do cotidiano das pessoas que habitam os centros urbanos é a convivência em organizações. Grande parte dessas pessoas passa mais da metade de suas vidas vinculadas a algum tipo de organização, seja ela uma empresa capitalista, seja uma entidade sem fins lucrativos ou mesmo uma instituição pública ou privada.

O comércio, os bancos, as universidades e faculdades, as empresas de transporte, de prestação de serviços, a indústria em todas as suas modalidades, os tribunais e ministérios, as religiões, os meios de comunicação, os exércitos e as associações de voluntariado, enfim, todas essas formas de associação com fins produtivos são lugares que se organizam em torno de pressupostos e fundamentos relativamente simples em sua concepção, mas extremamente complexos em suas ramificações e conseqüências.

A rotina nesses ambientes é mantida - dentre outros recursos - mediante a utilização de práticas rituais. Tais práticas estão a serviço da estabilização e da manutenção da ordem, colaborando, assim para a preservação do poder constituído. Os processos em que os rituais são demandados, normalmente são potencialmente 
conflituosos; os momentos ritualizados impedem a eclosão dos conflitos, apaziguando e dissolvendo atritos que, se não tratados, podem trazer conseqüências nefastas para os sujeitos e para a s organizações.

\section{A VIDA NAS ORGANIZAÇÕES}

A vida nos escritórios e repartições públicas é uma das mais duras experiências a que nos submetemos. Rotineira por natureza, repetitiva e pontuada por signos desgastados, essas práticas cotidianas produzem conseqüências agradáveis, desagradáveis, compensadores ou danosas que contaminam todas as dimensões da vida de um sujeito. Seus afetos, preferências, decisões, crenças e temores estarão irremediavelmente condicionados pelos humores, sabores e dissabores experimentados na sua vida "profissional". Até mesmo as rejeições ou adesões incondicionais a essas influencias possuem vetores claramente determinados pelos mesmos fatores que desejam afastar.

As organizações possuem, assim, papel fundamental na vida dos indivíduos e não há como fugir do seu poder coercitivo. Conforme nos diz Richard Hall, ${ }^{(1)}$ "desde que nascemos estamos vinculados a alguma instituição: o nascimento é registrado num cartório, seguido de um rito religioso de iniciação e adesão institucional." A família, em sua conformação tradicional, funciona à moda de uma organização formalmente constituída. O colégio, a universidade, os grupos musicais, de amizade, esportivos, são lugares de vida organizada e parametrizada em normas, regras, hábitos consuetudinais. $\mathrm{O}$ primeiro emprego e a primeira demissão, a inclusão e a exclusão em grupos de afinidade, as estratégias e as farsas de dominação nos relacionamentos profissionais são, dentre outras, situações nas quais o indivíduo experimenta o quão árdua e depressiva pode ser a dependência das organizações.

Para muitos, viver em organizações é essencial para assegurar condições físicas e psicológicas de subsistência e prazer. O prazer do reconhecimento, a retribuição e o sucesso das estratégias de dominação constituem motivos mais que suficientes para permanecerem nas organizações e cultivarem ali os sentidos maiores de suas vidas. Para esses, os revezes necessitam ser entendidos como acidentes de percurso, conseqüências inevitáveis de um jogo no qual seus parceiros são também seus opositores ou mesmo condições inevitáveis de aprendizagem e crescimento. 


\section{OS RITOS E A SEGUNDA REALIDADE}

Conforme nos sinaliza uma vasta literatura da área da sociologia e da comunicação organizacional, uma organização resulta do encontro de duas ou mais pessoas que pretendem atingir certos objetivos comuns em atividade cooperativa. Para tanto, integramse comunicativamente, coordenam-se e recolhem do meio ambiente os insumos de que necessitam. Transformam esses insumos e os devolvem ao ambiente

Nenhum tipo de organização pode, então, prescindir da comunicação, condição para que as pessoas compartilhem objetivos comuns e estabeleçam estratégicas consensuais para atingi-los. E não só as pessoas, como também todo ser vivo necessita celebrar pactos para instaurar situações comunicativas na vida em comum. Segundo Cyrulnik: ${ }^{(2)}$

É o ritual que estrutura a comunicação entre dois organismos, duas pessoas ou dois povos diferentes. Esse ritual pode ser descrito em termos etológicos como um verdadeiro intermediário sensorial que permite harmonizar os corpos, comunicar emoções e trocar idéias. Quando o ritual não consegue se implantar, irrompe a violência, porque a violência é necessária à sobrevivência. (p.102)

Os comportamentos rituais remontam às práticas religiosas e são atividades eminentemente culturais através das quais se crê ser possível resolver problemas que de outra forma resultariam insolúveis e de difícil convivência. ${ }^{(3)}$

O estudioso tcheco da escola semiótica da cultura, Ivan Bystrina, denomina o ambiente da cultura como uma "segunda realidade" na qual tudo pode ser resolvido graças à competência simbólica que o homem desenvolveu para recriar e superar, em outras esferas, suas impossibilidades.

A "primeira realidade" é formada pelas dimensões biológicas e sociais da vida (não apenas humana) nas quais a comunicação é realizada pela ação dos códigos hipolingüais (biológicos) e dos códigos linguais (sociais). A "segunda realidade", a realidade da cultura, é onde se dão os ritos, os mitos, as invenções, alucinações, criações imaginárias, enfim toda a produção simbólica do ser humano, único animal dotado de metaconsciência e, portanto, capaz de abstrair e sonhar acordado.

As organizações são constructos sociais (pela definição sociológica) e ambientes culturais (pelo entendimento antropológico e semiótico), nos quais se constrói, se destrói e se mantém convicções, crenças, fundamentos e pilares simbólicos capazes de sustentar a coesão, a ação solidária de tantos quantos delas fazem parte. 
Nelas vigoram aqueles signos que Bystrina denomina "terciários ou hiperlingüais". São os códigos responsáveis pelos arranjos sígnicos e textuais que vão além da técnica, do utilitarismo e das necessidades biológicas. Segundo Santos, ${ }^{(5)}$ "esses códigos são centrípetos; não se referem ao mundo exterior. Apontam para si mesmos e criam realidades próprias que, do ponto de vista das necessidades materiais, não têm utilidade alguma”. (p.107) Os textos produzidos nessa dimensão são denominados, por Bystrina, textos criativo-imaginativos. São eles as obras de arte, todos os fenômenos e objetos estéticos, as sensações, loucuras de todos os gêneros, as especulações filosóficas e as crenças religiosas, o fundamentalismo, os fanatismos políticos, religiosos e corporativos, enfim, tudo o que é baseado em signos de sensação, qualidade de sentimento, de "primeiridade" peirceana ${ }^{1}$.

Se prescindíveis do ponto de vista material, os textos criativo-imaginativos são imprescindíveis à sobrevivência cultural: pertencem a esse território "hiperlingüístico" todas as criações simbólicas do homem para superar os problemas trazidos pela ação dos códigos hipolingüais e lingüísticos, tais como as estruturas de consolação, os mitos, os rituais, as ideologias de qualquer espécie, as religiões, a educação, os meios de comunicação de massa ${ }^{2}$, etc. ${ }^{(7)}$

Nas organizações, os ritos não só assumem função privilegiada na instauração e manutenção da coesão solidária dos grupos, como também são fundamentais para que as estruturas de poder sejam capazes de manter em funcionamento os diversos níveis de dependência (hierarquias) nos quais se instalam os vínculos entre as pessoas.

\section{RITOS E MITOS ORGANIZACIONAIS}

A relação entre mito e rito é bastante estreita. Há entre esses dois fenômenos uma interdependência que é assim explicada por Eudoro de Souza: ${ }^{(8)}$

Nesse momento [...] mito e rito constituem-se como dois aspectos do mesmo fenômeno: o rito, como mito em atos; o mito, como rito em imagens. No drama, que, por assim dizer, seria a vivente matriz da consciência religiosa, as imagens aderem intimamente aos atos, e de tal modo, que ato e imagem podem e devem ser considerados como dois pólos - o anímico e o corpóreo - da mesma entidade

\footnotetext{
${ }^{1}$ Traçamos aqui um paralelo com a Teoria Geral dos Signos, de Charles Sanders Peirce, na qual a primeira categoria "da mente de da natureza", a primeiridade, é caracterizada pela fluidez dos signos que possui, pela inapreensão, pela sensação e pela qualidade dos fenômenos e objetos. ${ }^{(6)}$

2 Os meios de comunicação de massa, os "mídia" são aqui incluídos de acordo com a sua natureza formativa, sua competência de criar segundas realidades, ou ainda pelo fato de se constituir numa das mais eficiências instâncias "doadoras de signos".
} 
dramática: o mito é o corpo do rito, o rito é a alma do mito, e a síntese é drama ritual, em que os deuses se apresentam aos homens e os homens conhecem a presença dos deuses. (p.97)

Eudoro de Souza refere-se aqui ao mito como narrativa de um tempo, um fato ancestral, exemplar ou paradigmático, que precisa ser lembrado e atualizado pelo rito. Assim, os ritos são lugares e tempos de reificação de mitos: ${ }^{(9)}$

Toda festa religiosa, todo o tempo litúrgico representa a reatualização de um evento sagrado que teve lugar num passado mítico, "no começo". Participar religiosamente de uma festa implica [...] a reintegração do tempo mítico reatualizado pela própria festa. (p.81-82)

\begin{abstract}
Alinhado com Eudoro de Souza e Mircea Eliade, Tenório dos Santos ${ }^{(5)}$ afirma que "rito" e "mito" são elementos complementares e interdependentes que formam uma unidade complexa, unidade essa que é a responsável pelas características individualizantes de uma dada cultura.
\end{abstract}

Numa organização, os momentos ritualizados ocorrem mais freqüentemente do que imaginamos e sua contribuição para a formação da identidade e da imagem do grupo é bem mais intensa quanto mais impregnado de signos simbólicos forem as cerimônias institucionais.

Podemos observá-los quando, por exemplo, da assinatura de convênios, parcerias, lançamento de novos produtos, ao final de um exercício contábil (balanços), na apresentação dos resultados financeiros, nas comemorações de datas importantes para a organização, na inauguração de uma nova obra, um novo prédio, uma nova agência, quando da estréia da empresa num novo mercado, nas aberturas de novas frentes de comércio, etc.

\title{
Os Deuses e as organizações
}

$\mathrm{Na}$ base dessas festividades, tácita ou estridentemente são revividos alguns mitos de autoridade e de poder encarnados na história da empresa, na figura de seus fundadores, pioneiros, principais empreendedores, etc.

Há também relações intensas entre mitos modernos e mitos arcaicos. Um exemplo muito interessante de algumas presenças míticas nos rituais organizacionais/administrativos comuns nas empresas atuais pode ser encontrado em "Deuses da Administração", de Charles Handy. O autor compara o que ele denomina "filosofias de administração" aos deuses gregos Zeus, Apolo, Atena e Dionísio. Tais 
"filosofias" são modelos culturais nos quais as organizações, segundo o autor, se enquadram.

Para cada deus, Handy faz corresponder uma figura e uma classificação de cultura.

Assim, Zeus personifica organizações que "usam" uma cultura que tem a divisão do trabalho baseada em funções ou produtos ligados às idiossincrasias do dono ou do administrador; em torno dele se arma uma teia e nos pontos de convergência das linhas dessa teia estão os empregados de confiança de Zeus, o chefe, dono autoritário. Por isso, esse modelo é chamado também de cultura de clube.

Apolo personifica empresas que se organizam em torno de funções ou tarefas e não em torno de personalidades; assemelham-se a um templo grego, cuja força vem dos pilares (papéis, e divisões de funções); é o modelo das burocracias (cultura da função) que multiplica papéis, expande procedimentos, valoriza as rotinas, a previsibilidade e a estabilidade, concentrando-se nos detentores de papéis (chefes especializados).

Atena representa a cultura da tarefa e é representada pela rede onde, a partir de um problema, recolhe-se do meio ambiente os insumos e recursos para solucioná-lo; essa rede ou trama funciona como uma reunião de unidades de comando interligadas entre si, mas autônomas na busca de soluções; quando cada uma cumpre sua tarefa, o todo se beneficia.

Dionísio representa a cultura existencial, as organizações que promovem o indivíduo, a exemplo das cooperativas de trabalho e de produção, que Handy ilustra como uma constelação de estrelas circunscritas; nelas não há patrão, mas coordenadores das causas comuns.

Nas analogias de Handy observamos claramente as relações que interligam mitos aos ritos. Tudo o que força e atualiza uma crença apolínea ou dionisíaca, por exemplo, merece e precisa ser comemorado ritualmente para que a organização reforce seus fundamentos e mantenha-se, assim, com força coercitiva capaz de não permitir que seus integrantes se desagreguem.

Zeus, o administrador que detém as soluções, paternaliza empregados e clientes. A relação mantida com o personagem é mediada por elementos rituais que se manifestam, por exemplo, numa forma atípica de cumprimentar (ritos de saudação, segundo Van Gennep $^{3}$ ), de se comportar, de responder e dirigir o olhar, de reagir em adesão, etc. Apolo,

\footnotetext{
3 “Toda sociedade geral pode ser considerada como uma espécie de casa dividida em quartos e corredores, com paredes [...] e portas de comunicação [...] esses compartimentos são isolados uns dos outros e para passar de um ao outro são necessárias formalidades e cerimônias." 
filho de Zeus, ilumina (medeia) as relações nas organizações e é esse o fundamento de suas funções: é o gerente/organizador que seleciona o que deve ser feito para promover a passagem do impossível (ou difícil) para o possível (atingível). Atena, também filha de Zeus, desloca a mediação para o trabalho que realiza, tecendo a rede que busca soluções simbólicas para os problemas do cotidiano e Dionísio, nascido da coxa de Zeus, subverte o princípio do trabalho para a organização (o corpo da cultura) colocando-a a serviço do indivíduo (a organização trabalha para o sujeito).

Nesse último caso, a organização assume o lugar de Apolo ou de Atena. Somente através dela e por ela o sujeito consegue superar (pelo consenso simbólico coletivo) os problemas do cotidiano. É importante ressaltar que o nepotismo presente na analogia de Handy (talvez não por coincidência) mantém muita relação com a prática das empresas, tanto públicas quanto privadas.

\section{RITOS DE PASSAGEM}

Além de costumeiros e usuais na marcação de diversos estilos de relacionamento nas organizações, os ritos aparecem com muita força nos momentos em que acontecem mudanças, em que há passagem de uma situação a outra. Esses "momentos" podem ocorrer quando ocorre agregação (entrada), desagregação (separação, saída) ou indefinição (saída, marginalização).

Arnold Van Gennep ${ }^{(12)}$ nos diz que os ritos de desagregação são ritos que sinalizam a saída do indivíduo de um grupo, de uma situação ou de um estado para outro. São muito comuns nas organizações as solenidades de despedida, recheadas de emocionalidades, rememorações de fatos e sensações passadas. Normalmente recheadas de discursos nos quais as estruturas de consolação $^{(11)}$ imperam como justificativa e explicação para a separação, tais solenidades são - como ademais todos os ritos - bastante previsíveis, redundantes e essencialmente afirmativas. Os discursos são acompanhados de linguagens gestuais, corporais pouco flexíveis, olhares padronizados e ritmicamente sincopatizados para produzir efeitos paradoxais/padronizados de lástima e alegria, frustração e otimismo. Por mais que predominem nesses rituais um ou outro sentimento mais extremado, a tendência é encerrar-se em resignação, conforto e consolação, "azeitando" a organização para entender, assimilar, superar e esquecer rapidamente o acontecimento. 
Os ritos de agregação preparam a organização para a novidade, de forma a preservá-la de perigos que possam desestabilizar seu funcionamento. Tem como objetivo integrar indivíduos e situações novas com um mínimo de custo emocional/psicológico, preservando o equilíbrio do sistema. As cerimônias de posse são marcadas, normalmente, por olhares e atitudes receptivas, discursos verbais nos quais predomina a adesão às causas do sistema, anúncio de mudanças suaves, promessas de continuidade e de correspondências às expectativas dos integrantes do grupo. Os rituais de agregação, segundo Van Gennep denominados "pós-liminares" têm a finalidade primordial de integrar e garantir a continuidade dos sistemas que já estavam em funcionamento antes da novidade. Servem assim à preservação das estruturas constituídas do poder, caracterizando-se fortemente pelas intenções conservadoras e reacionárias.

Já os ritos de indefinição (de margem, de saída) são marcados pela dúvida e pela transição, pela provisoriedade e pela indefinição. São chamados de ritos liminares pois evidenciam a posição intermediária do objeto ritualizado, tendendo a estabilizá-lo em locais de passagem, de transição, de espera. Os rituais dessa natureza tendem a acentuar a perda da situação anterior e as possibilidades futuras (ainda incertas) com algum grau de garantia, ainda que paradoxalmente "duvidosa". As mensagens são carregadas de "desejos" e "expectativas" de confirmação, têm caráter reticencioso, não negam nem afirmam, demonstram alento e ansiedade, transparecendo certas tendências oscilantes entre pólos negativos e positivos. As vantagens de estar "dentro" ou estar "fora"(7) são relativizadas em vantagem de um certo alívio pela perda da fidelidade a um ou a outro sistema. Os comportamentos rituais, nesses casos, são evasivos, dissimulados, marcados por um certo incômodo indisfarçável e, até mesmo, assumido como natural.

De modo geral, nessas ocasiões, alguns sintomas evidenciam o esforço de passagem como o enfrentamento corajoso de um desafio, Passar de uma situação a outra, de um sistema conhecido a um outro desconhecido (ou pouco conhecido), de uma certeza para uma dúvida (ou vice-versa) não é algo que possa ser suportado sem um mínimo de stress, de ansiedade e temor.

As manifestações rituais precisam, por isso, incorporar marcas físicas que reforcem e representem simbolicamente o discurso da transição. Os estandartes, tapetes vermelhos, carros de luxo, trajes cerimoniais, bottons, insígnias, galhardetes, a farta exposição de marcas-símbolo e cores institucionais, almoços ou jantares solenes, shows artísticos, distribuição de brindes, presentes, ornamentação ostensiva dos ambientes são algumas 
marcas que incorporam a lembrança e os propósitos formalmente instituídos no ritual. Até mesmo o "cafezinho" de negócios ou a caneta que foi utilizada para assinar o contrato, constituem signos rituais de primeira ordem, sem os quais a força da passagem não teria como ser dissolvida, amenizando o incômodo da mudança.

Os rituais, portanto, se prestam a fortalecer as marcas da passagem, não deixando dúvidas quanto à consagração de uma mudança, qualquer que ela seja. A ausência desses pequenos ou grandes cerimoniais pode comprometer as relações, afrouxar os laços de um acordo ou mesmo desacreditá-lo, não somente perante as leis instituídas, mas também - e principalmente - entre as partes que promovem o encontro.

Os ritos preenchem aquelas regiões - que Pross denomina "zonas cinzentas" - com os signos dos sistemas vizinhos envolvidos em seus limites, dificultando ou mesmo inviabilizando o conflito resultante de uma provisória desorientação sígnica.

\section{O Underground}

Porém, nem sempre as zonas de passagem são ritualizadas. Harry Pross nos lembra que esse comportamento gera a constituição de lugares de encontro não reconhecíveis, transgressivos e à margem do reconhecimento. Entretanto, são esses espaços lugares privilegiados da formação de massa crítica para os sistemas que não conseguem abarcá$\operatorname{los}:{ }^{(7)}$

Para a política e a publicidade, o espaço intermediário como zona a meio do caminho entre a comunicação orientada ao domínio e a tendência à publicação, é indispensável. Corredores, passagens estreitas, ante-salas, vãos de escada, encontros no trem, viagens casuais em comum, são lugares e ocasiões onde pode surgir um intercâmbio, já que nenhum dos interlocutores está sujeito à coação simbólica da ordem fechada que o separa do exterior. Os verdadeiros lugares de encontro são os intervalos, os espaços e tempos intermediários da práxis. (p. 67)

A comunicação que acontece fora dos espaços circunscritos pelas intenções do discurso das organizações são, normalmente, instigadas pela surpresa de encontros fortuitos. As zonas intermediárias entre um sistema e outro, estão, de cerca forma, descomprometidas com as coações de qualquer sistema e são, portanto, lugares onde tudo é possível. Elas acontecem em diversos momentos do dia-a-dia e podem nos levar a sentilas como desorientação. Assim, é comum nos lembrarmos, nos corredores, de algo que deveríamos ter dito ou observado quando estávamos "dentro" do ambiente, do sistema.

Da mesma forma, não é tão raro ocorrer uma lembrança inusitada no caminho de casa para o trabalho, do trabalho para casa, do escritório da empresa para a agência do 
banco, e assim em inúmeras situações de trânsito. É preciso notar que o trânsito de automóveis, por exemplo, é também ritualizado e constitui, portanto, um sistema. Mas como "sistema" interposto para passagem entre outros dois sistemas (o trabalho e o lar, por exemplo), permite um certo relaxamento das tensões que os ambientes de saída e de chegada nos impõem.

Quando Pross se refere ao fato de que, para as ações políticas e publicitárias, os espaços intermediários são indispensáveis, ele está afirmando, de outra maneira, que essas atividades não podem prescindir dos novos significados gerados fora de seu controle. As organizações, ao ritualizarem seus momentos de passagem, tentam obstruir a entrada de contribuições marginais ou estranhas ao sistema, mas não podem impedir que elas penetrem pelas fendas que o próprio sistema não tem condições de controlar. É por esses lugares que ele respira e areja suas ideologias, ainda que necessite demonstrar força repressiva para preservar o poder do núcleo organizador.

\section{O Poder apaziguador dos ritos}

É nesse sentido que as ritualizações servem ao poder instituído nas organizações, sejam empresas, autarquias, entidades públicas, grupos informais ou organizações voluntárias. Os ritos são, em todas essas organizações, ferramentas compreensivelmente eficazes de manutenção das estruturas do poder.

Porém, é preciso lembrar que os ritos só se prestam a evitar atritos porque estão a serviço de uma tendência manifesta no comportamento demasiado humano: o de preservação da vida, da espécie, das rotinas e das garantias, ainda que ilusórias, de segurança.

Assim como o fenômeno da comunicação, os ritos atuam nivelando e apaziguando diferenças. O necessário trânsito entre afinidades, diferenças e indiferenças não pode se dar sem cuidados especiais. Tais cuidados, ainda que não despersonalizem a novidade que vem de fora ou o incômodo que é banido de dentro, tornam a passagem menos onerosa, suportável.

Mircea Eliade, Van Gennep, Ernest Cassirer Roger Caillois, dentre outros, são bastante criteriosos aos vincular a necessidade de mitos e ritos à uma certa tendência unificadora que move o espírito humano, tão castigado pela consciência da falta e pelas sucessivas experiências de dissolução e separação. 
É Medina Rodrigues, num texto intitulado “Afinidades e Diferenças" que nos dá um indicador bastante seguro para entendermos não apenas as tendências unificadoras do logos humano, mas também, por extensão, as características e pacificadoras dos ritos e dos mitos: ${ }^{(14)}$

\begin{abstract}
Uma das características da vida cotidiana está na afinidade que encontramos entre coisas, pessoas e fenômenos [...] Essa experiência, sem dúvida uma das mais importantes da órbita humana, esse reinado quase absoluto da afinidade encaminha, de certa forma, nossas paixões, nosso afeto, dando forma e peso a cada um [...] o logos grego nada mais é do que a projeção das simpatias e das semelhanças que os homens estabelecem ao longo da existência. Nos seus limites mais amplos, esta afinidade está de mãos dadas com o sentido e totalização. (p. 3)
\end{abstract}

Mitos e ritos constituem parte e processo de chegada a esse logos ao qual Medina Rodrigues se refere, esse telos que se coloca como inatingível, mas desafiadoramente provocante na ordem natural dos eventos organizacionais: ${ }^{(14)}$

O mundo, ao que parece, tem um sentido unificador, tem um movimento fisicamente determinado, um telos, uma ordem natural dos eventos que não podem se atropelar. Não é possível haver saltos nessa dinâmica; se algum salto existe na natureza ele está previsto pela própria natureza. (p. 3-4)

Com base nas idéias de Medina Rodrigues, arriscamo-nos a afirmar que os saltos da imprevisibilidade, os tropeços e abreviamentos súbitos do transcurso natural dos eventos, da periodicidade esperada nos planejamentos organizacionais são acidentes (também naturais) que não podem ser razoabilizados senão pela interferência dos ritos. Ao evocarem mitos que restabelecem, em outro lugar (sagrado, arcaico, fundante), a unidade aparentemente perdida, os ritos funcionam como conjunções que devolvem à frase do fenômeno ou do acontecimento a sua plástica natural e possível (porque esperada e assimilável por aqueles que integram o ambiente no qual ela atua), preservando a gramática e a ordem de que todo sistema necessita.

\title{
AS NOVAS ORGANIZAÇÕES E OS RITOS DO UNDERGROUND
}

Entretanto, há situações nas quais as ritualizações de passagem não reatualizam conjunções capazes de restabelecer o tecido necrosado dos desacertos organizacionais. Quando o conflito (declarado ou velado) entre sistemas diferentes perdura sem definição durante algum tempo, ele tende a ser preenchido com signos próprios. Tal fenômeno não constitui uma "regeneração", mas numa nova "geração", um novo espaço de poder e 
circunscrição que, para afirmar-se, necessitará estabelecer-se, ritualizando seus procedimentos.

Só então podemos entender porque os sindicatos se configuram como instituições: é que esses espaços são ocupados pelos signos do underground. Sobre esse fenômeno, assegura Pross: ${ }^{(7)}$

O símbolo não tem valor apenas para assegurar que existe algo que está em lugar de outro algo, mas também por incluir a questão do valor. Esta questão quer encontrar uma resposta à pergunta de qual é a supraordenação da supraordenação e assim até chegar a uma instância ultima; e, ao contrário, a partir de uma instância última deduz as subordinações como algo coordenado com esta última instância. A significação dos signos não reside unicamente naquilo que designam; reside também na possibilidade de tornar significativo o designado, criar objetos do símbolo. Assim procedem a literatura, a arte, a religião. Mas os sujeitos que permanecem nas passagens se conduzem de forma distinta. Criam deles mesmos símbolos do underground, os quais, ao final das contas, são também inacessíveis aos outros, uma vez que pertencem a uma outra ordem, ou seja, o paradoxo do espaço intermediário. (p. 68-69)

Embora "estranhos", os signos da transição podem cristalizar-se e tornar-se, assim, autônomos e reconhecíveis. É o que acontece com muitos dos movimentos desconstrutivistas nas artes, na filosofia e na teoria do conhecimento: o discurso torna-se identificável pela sua estranheza peculiar, passando a caracterizar antiescolas como escolas (como ocorreu ao movimento dadaísta, por exemplo), a interdisciplinaridade como uma disciplina (como - infelizmente - soe acontecer com a Semiótica, nos meios acadêmicos brasileiros), enfim, transformando discursos fragmentários e incipientes em discursos individualizantes e autoritários (como os discursos político-partidários).

Os textos culturais formados nas zonas cinzentas entre organizações tendem a somar-se aos textos de outros sistemas, alterando e subvertendo as intenções estratégicas do discurso programado nas organizações já constituídas e que com elas confrontam. O hibridismo resultante desse incômodo, mas inevitável diálogo resulta em novos textos, agora gerados fora das órbitas organizacionais constituídas e, ainda, com pouca possibilidade de se montarem textos de novas organizações. Esses textos, provisórios e incipientes, são também terrivelmente perturbadores das zonas cinzentas da cultura.

A demarcação das novas fronteiras organizacionais instigadas pelos textos marginais e transgressores formados nas zonas intermediárias lhes dará uma conformação textual aceitável e as transformará, em pouco tempo, numa nova organização. Estrutura, fronteiras e expressão próprias (conforme nos diz Lotman em “A Estrutura do Texto 
Artístico") são os requisitos que toda e qualquer organização necessita para instaurar-se como sistema.

\section{REFERÊNCIAS}

1 Collado Carlos. Organización, información y comunicación. In: La Comunicación em las organizaciones. Ed. Trillas: México; 1996

2 Cyrulnik Boris. Os alimentos do afeto. Tradução Celso Mauro Paciornik. São Paulo: Ática; 1995.

3 Durkhein Emile. Formas elementares de vida religiosa. São Paulo: Martins Fontes; 1999.

4 Bystrina Ivan. Semiotik der Kultur - zeichen, texte, codes. Tubingen: Stauffenburg; 1989.

5 Santos Gérson T. A Morte, a cultura e o ocidente - um estudo intersemiótico. [dissertação]. Programa de Comunicação e Semiótica PUC. São Paulo; 1995.

6 Santaella, Lúcia. A teoria geral dos signos. Ática: São Paulo; 1995.

7 Pross Harry. La estructura simbólica del poder. Ed. Gustavo Gilli: Barcelona; 1980.

8 Souza Eudoro. Dioniso em Creta. São Paulo: Duas Cidades; 1973.

9 Eliade Mircea. O sagrado e o profano. Ed. Livros do Brasil-Lisboa: Lisboa; 1992.

10 Handy Charles. Deuses da administração. São Paulo: Saraiva; 1991.

11 Eco, Umberto et al. Socialismo y consolacion. Tusquets. Editor, Barcelona; 1970.

12 Van Gennep Arnold. Os ritos de passagem. Vozes: Petrópolis; 1978.

13 Cassirer Ernest. Linguagem e mito. São Paulo: Perspectiva; 1972.

14 Rodrigues Medina. Texto produzido para aula expositiva no curso de Comunicação e Semiótica da PUC/SP em agosto de 1992.

15 Lotman, Iuri et al. "Tesi per un analisi semiotica della cultura”. In: La Semiótica nei Paesi Slavi. Milano: Feltrinelli. A cura di Carlo Prevignano; 1979. p. 944-1020. 